\title{
Unit for Suicide Research, University of Gent,
}

\section{Belgium}

\author{
KEES VAN HEERINGEN
}

The Unit for Suicide Research was founded in 1996 with the aims of integrating and stimulating the study of suicidal behaviour, increasing the visibility of the research work, and providing evidence-based information to health policy-makers, the general public and the media. I am Director of the Unit, working alongside Professor Kurt Audenaert, Dr Katrien Bernagie, and psychologists Gwendolyn Portzky (Research Coordinator), Stephanie De Munck, Els Reyserhove and Hannelore Vromman. In this report I will summarise recent and current activities, which are carried out according to three lines of research: the study of the epidemiology of suicidal behaviour; the study of (the association between) biological and psychological characteristics of suicidal behaviour; and the development and evaluation of prevention strategies. Research is carried out in collaboration with other departments of the University of Gent (e.g. the Departments of Nuclear Medicine, Sociology, Radiopharmacy and Veterinary Medicine) and with a large number of other European research centres. The collaboration with Professor Hawton at the Oxford Centre for Suicide Research has been particularly important (Hawton \& Van Heeringen, 2000).

\section{WORK PERFORMED AND ONGOING}

\section{Epidemiological studies}

At a local level the epidemiology of attempted suicide has been investigated since 1986 (Van Heeringen \& De Volder, 2002). Since 1996 this study has been incorporated within the WHO/EURO Multicentre Study of Suicidal Behaviour (see for example Hjelmeland et al, 2002).

At a regional (i.e. Flemish) level the epidemiology of attempted suicide is studied by monitoring non-fatal suicide behaviour in the accident and emergency departments of five large general hospitals. The results of this study, which is funded by the Flemish Ministry of Health Policy, contribute to the epidemiological survey of suicide and attempted suicide by the Ministry of the Flemish Community.

Two follow-up studies have been carried out in large samples of people who have attempted suicide. The first was a 1-year follow-up study of more than 500 people who attempted suicide, and was a randomised clinical trial of the management of non-compliance following referral to out-patient after-care. This study showed that intensive outreach by a community nurse based in the accident and emergency department has a significant beneficial effect on compliance, and a nearly significant effect on repetition of attempted suicide (Van Heeringen et al, 1995). The second was a naturalistic 5-year follow-up study of 1000 people who attempted suicide, with the aim of assessing the effects of treatment on repetition of attempted suicide and on completed suicide (Van Heeringen et al, 2001).

The Unit participates in the Child and Adolescent Self-harm in Europe (CASE) study, which is coordinated by the National Children's Bureau in London and partly funded by the European Commission Daphne programme. This study is carried out in seven European countries and has two major objectives. First, in order to study the epidemiology of non-fatal suicidal behaviour among children and adolescents across Europe, self-harming behaviour is monitored in accident and emergency departments and in child and adolescent psychiatric facilities in a well-defined geographical area. Second, the occurrence of risk or protective factors (such as depression, hopelessness, anxiety, substance misuse, use of mental health care) of selfharming behaviour of 15- to 16-year-olds in the community is studied by means of a school-based questionnaire survey. Thus, data on approximately 30000 adolescents have been collected and are now in the process of statistical analysis.

The Unit participates in the European Review of Suicide and Violence Epidemiology (EUROSAVE) study group, which collects epidemiological data on suicide and violence in 12 European countries.

Psychiatric, personality-related and psychosocial data on suicide in children and adolescents and in psychiatric controls were recently collected using a psychological autopsy approach. The data are currently being analysed.

Two epidemiological studies have addressed suicidal behaviour in specific populations. First, the unit participated in the YUSEDER project, which was funded by the European Commission and which studied suicidal ideation and behaviour in the context of social exclusion among long-term unemployed youngsters. Second, the occurrence and risk factors of suicidal ideation and behaviour in homosexual and bisexual young people was studied, showing increased risks particularly among female homosexual or bisexual youngsters (Van Heeringen \& Vincke, 2000).

\section{Biological and psychological characteristics}

A first study in this domain addressed cortisol production and the association with monoamines and personality characteristics. Major findings included an increased 24-h urinary cortisol production in people who attempted suicide, which correlates significantly with scores on the personality dimension 'reward dependence' (Van Heeringen et al, 2000).

Recently, using in vivo functional neuroimaging we were the first to report on changes in type $2 \mathrm{a}$ serotonin $\left(5-\mathrm{HT}_{2 \mathrm{a}}\right)$ receptor binding in the prefrontal cortex of the brains of patients who had attempted suicide (Audenaert et al, 2001). We demonstrated that these changes correlate with levels of hopelessness, a core psychopathological characteristic of suicidal behaviour, and with trait-dependent regulation of anxiety (Van Heeringen et al, 2003). A further study of prefrontal cortex functions in patients who have attempted suicide has addressed verbal fluency and regional cerebral blood flow by means of a split-dose activation paradigm (Audenaert et al, 2002). Current research is endeavouring to study the role of the prefrontal cortex in the pathophysiology of suicidal 
behaviour, by means of comparative neuropsychological and functional neuroimaging studies in aggressive compared with suicidal individuals, and using neuroimaging studies of the prefrontal serotonergic system in aggressive dogs (Peremans et al, 2003).

\section{Development and evaluation of prevention strategies}

Researchers from the Unit for Suicide Research have evaluated the first phase of the Flemish suicide prevention programme in 2000 , and have been involved in developing the new programme, which was presented by the Minister of Health Policy in December 2002.

Other prevention-related activities include participation in the Cochrane systematic review of the efficacy of psychosocial and pharmacological interventions in preventing repetition of deliberate selfharm (Hawton et al, 1998; Townsend et al, 2001). Using a controlled design, the effects of a school-based suicide prevention programme on attitudes towards suicide and help-seeking behaviour (among other outcome measures) are currently being studied.

\section{NEW INITIATIVES AND CHALLENGES FOR THE FUTURE}

New international collaborative epidemiological studies of suicidal behaviour are being prepared. Two other projects will address the study of clinical, neuropsychological and neurobiological characteristics using a process approach to suicidal behaviour (Van Heeringen, 2001), including the detailed study of medically serious suicide attempts.

The study of the role of the prefrontal cortex in the development of suicidal behaviour will continue to be a major focus of research. New receptor ligands are currently being developed for functional neuroimaging studies of receptors for serotonin and other neurotransmitters, addressing their role in the neurobiological modulation of neuropsychological functions using single photon emission computed tomography and positron emission tomography. A combined molecular genetic and functional neuroimaging study of suicidal behaviour is currently being prepared

KEES VAN HEERINGEN, PhD, MD, University Department of Psychiatry, University Hospital, De Pintelaan I85, 9000 Gent, Belgium. Tel: +32 (0)9 240 4375; fax: +32 (0)9 240 4989; e-mail: cornelis.vanheeringen@rug.ac.be

for local and international collaborative studies.

Collaboration with the Centre for Eating Disorders of the University Hospital Gent has resulted in a joint research proposal addressing the study of clinical, psychological, biological (Audenaert et al, 2003) and personality-related (Vervaet et al, 2003) similarities and differences in the trait-dependent predisposition for eating disorders and suicidal behaviour.

Finally, two studies will investigate the effects of psychotherapy (i.e. mindfulnessbased cognitive therapy) and pharmacotherapy (with selective serotonin reuptake inhibitors), respectively, on the neuropsychological and neurobiological correlates of suicidal behaviour.

\section{CONCLUSIONS}

While there was no doubt about the necessity of establishing a unit for suicide research in Belgium in view of the high rates of suicidal behaviour, it was uncertain whether such a unit would be viable because of limited national or Flemish research funding opportunities. However, owing to the organisation of scientific events such as the 7th European Symposium on Suicide and Suicidal Behaviour in Gent in 1998, and a substantial number of publications, the unit has received increasing attention from regional, national and international authorities. Scientific collaboration at local and international levels has been decisive in developing the unit.

It appears that the aims of the unit, as described at the start of this report, have been met. Based on their dedication, scientific curiosity and persistence, the researchers look forward to continuing their work and continuing to contribute to the understanding and prevention of suicidal behaviour.

\section{REFERENCES}

Audenaert, K., Van Laere, K., Dumont, F., et al (200I) Decreased frontal serotonin 5-HT2a receptor binding potential in deliberate self-harm patients. European Journal of Nuclear Medicine, 28, 175-182.
_, Goethals, I., Van Laere, K., et al (2002) SPECT neuropsychological activation procedure with the Verbal Fluency Test in attempted suicide patients. Nuclear Medicine Communications, 23, 907-916.

_ , Van Laere, K., Dumont, F., et al (2003) Decreased 5-HT2a receptor binding in patients with anorexia nervosa. Journal of Nuclear Medicine, 44, 163-169.

Hawton, K. \& Van Heeringen, C. (2000) The International Handbook of Suicide and Attempted Suicide. Chichester: John Wiley \& Sons.

\section{_ , Arensman, E., Townsend, E., et al (1998)}

Deliberate self-harm: systematic review of efficiency of psychosocial and pharmacological treatments in preventing repetition. BMJ, 317, 44I-4I7.

Hjelmeland, H., Hawton, K., Nordvik, H., et al (2002) Why people engage in parasuicide: a crosscultural study of intentions. Suicide and Life-Threatening Behavior, 32, 380-393.

Peremans, K., Audenaert, K., Coopman, F., et a (2003) Estimates of regional cerebral blood flow and 5 $\mathrm{HT}_{2 \mathrm{a}}$ receptor density in impulsive aggressive dogs with TC-99m ECD and I-I23 5-I-5-Rql I50. European Journal of Nuclear Medicine, in press.

Townsend, E., Hawton, K., Altman, D. G., et al (200I) The efficacy of problem-solving treatments after deliberate self-harm: meta-analysis of randomized controlled trials with respect to depression, hopelessness and improvement in problems. Psychological Medicine, 31, 979-988.

Van Heeringen, C. (200I) Understanding Suicida Behaviour: The Suicidal Process Approach to Research Treatment and Prevention. Chichester: John Wiley \& Sons.

— \& De Volder, V. (2002) Trends in attempted suicide in adolescents and young adults in Gent, 1986-1995. Archives of Suicide Research, 6, 1-8.

— \& Vincke, J. (2000) Suicidal acts and ideation in homosexual and bisexual young people: a study of prevalence and risk factors. Social Psychiatry and Psychiatric Epidemiology, 35, 494-500.

_ , Jannes, C., Buylaert, W., et al (1995) The management of non-compliance with referral to outpatient after-care among attempted suicide patients: a controlled intervention study. Psychological Medicine, 25, 963-970.

_, Audenaert, K., Van de Wiele, L., et al (2000) Cortisol in violent suicidal behaviour: association with personality and monoaminergic activity. Journal of Affective Disorders, 60, 181-189.

_, _ \& Portzky, G. (200I) Risk factors for the repetition of suicidal behaviour: a 5-year follow-up study. In Suicide Risk and Protective Factors in the New Millenium (ed. O. Grad). Ljubljana: Cankarjev Dom.

_ , _ , Van Laere, K., et al (2003) Prefrontal 5-HT2a receptor binding potential, hopelessness and personality characteristics in attempted suicide patients. Journal of Affective Disorders, 74, 149-158.

Vervaet, M., van Heeringen, C. \& Audenaert, K. (2003) Cognitive and behavioural characteristics are associated with personality dimensions in patients with eating disorders. European Review of Eating Disorders, II, $1-16$. 